\title{
TOWARDS ORGANISATIONAL SIMPLEXITY - A SIMPLE STRUCTURE IN A COMPLEX ENVIRONMENT
}

pages: $43-53$

\author{
KATARZYNA TWOREK, KATARZYNA WALECKA-JANKOWSKA, \\ ANNA ZGRZYWA-ZIEMAK
}

\begin{abstract}
A B S TRACT
The article contributes to the discussion on the validity and ways of simplifying modern organisations. There is an increasing focus on simplifying organisations, especially their organisational structures. However, the environment of contemporary organisations is increasingly complex, dynamic and uncertain. Therefore, the postulate of simplicity seems to question Ashby's law stating that one kind of variety must be balanced by a different kind of variety. To cope with the indicated discrepancy, it is assumed that the simplification of some elements of an organisation is only possible due to the excessive complexity of others. The paper aims to verify the concept of organisational simplexity developed by e Cunha and Rego, which postulates the fit between simple structural solutions, complex workforce and complex environment. However, organisational performance is a factor verifying the legitimacy of the fit. The literature study explored the contradiction inherent in the postulate on the simplification of modern organisations. The contingency theory provided a major framework for the study. The research hypothesis was developed and empirically verified. The empirical study targeted 1142 organisations operating in Poland and Switzerland, different by their industry, size and the form of ownership. To verify the hypothesis, a statistical analysis was carried out, and the multiple correspondence analysis (MCA) method was used. The main result of the critical literature analysis is the finding that theoretical indications for simplifying modern organisations are fragmented, mainly focused on simplifying selected elements of an organisation, not considering the contradiction inherent in the postulate of simplicity related to environmental features and not verified empirically. The notion of the simplexity has been adopted, and it treats the simplicity and complexity as interrelated issues conditioned by situational factors. According to the empirical research results, the fit has been revealed between the degree of structure simplicity, the workforce complexity and the environment features.
\end{abstract}

KEY WORDS

complexity, organisational structure, organisational performance, simplexity, simplicity, workforce, contingency approach

DOI: $10.2478 / e m j-2019-0032$
Corresponding author:

Katarzyna Tworek

Wrocław University of Science and Technology, Poland e-mail: katarzyna.tworek@pwr.edu.pl

Katarzyna Walecka-Jankowska

Wrocław University of Science and Technology, Poland e-mail: katarzyna.walecka-jankowska@ pwr.edu.pl

Anna Zgrzywa-Ziemak

Wrocław University of Science and Technology, Poland e-mail: anna.zgrzywa-ziemak@pwr.edu.pl

\section{INTRODUCTION}

The quest for simplicity as an act of opposition to the complexity of the world of organisation and management is becoming more visible (Hopej et al., 2017). It is not surprising, as several empirical studies deliver hard data proving that excessive complexity of an organisation has a significant negative impact on productivity, profits, the level of customer service, corporate governance and product development (Collinson \& Jay, 2012; Leff \& Zolkos, 2015). However, the research conducted by The Economist shows that modern organisations are perceived by managers as too complex: almost half of 331 managers stated that their organisations were very or extremely complex - even too complex to manage (Leff \& Zolkos, 2015). What is more, the organisational complexity 
seems to be increasing even though for almost two decades, the management tools and some more comprehensive concepts of simplifying organisations have been developing (e.g. Eisenhardt \& Sull, 2001; Maeda, 2006; Ashkenas, 2007; Osbert-Pociecha, 2013; Collinson \& Jay, 2012; Segall, 2013; Brandes, 2013; Hopej et al., 2017).

The question arises why the efforts to simplify organisations do not bring the expected results? It is argued that there is an unresolved contradiction in the postulate of the organisational simplification as it questions Ashby's law (Cunha \& Rego, 2010; HopejKamińska et al., 2015; Hopej et al., 2017). Modern organisations function in an increasingly more complex, dynamic and uncertain environment. Therefore, according to Ashby's law stating that one kind of variety must be balanced by a different kind of variety, modern organisations should be increasingly more complex (not simple!). As a result, any concept of simplifying organisations or simplifying any element of an organisation (e.g. organisational strategy, structure, processes or products offered) must face this contradiction.

The article uses the adapted concept of organisational simplexity developed by e Cunha and Rego (2010), as it seems to cope adequately with the indicated discrepancy. The authors argue that the complexity and simplicity should permeate each other for an organisation to gain a competitive advantage and achieve success. According to Cunha and Rego (2010), when the complexity of the environment is increasing, the simplification of some elements of an organisation is only possible due to the excessive complexity of others. In particular, they postulate the necessity of the fit between the degree of organisational structure simplicity, the workforce complexity and the complexity of the organisational environment. The concept of organisational simplexity is very promising, as it supports the simplification of some elements of an organisation operating in a complex environment (according to business practitioners' expectations) and it is in line with Ashby's law. In this paper, the attempt to verify the concept of organisational simplexity has been made. A question emerges: Is there a fit between the simplicity of the organisational structure, workforce complexity and selected features of the organisational environment (complexity, dynamics and uncertainty)? In other words, is it justifiable to formulate such a concept as organisational simplexity? Therefore, this paper mainly aims to verify the proposed concept of simplexity and confirm that such a fit (simplexity) leads to enhanced organisational performance.
The perspective of the contingency theory is adopted since it assumes that enhanced organisational performance results from fitting organisational features to contingencies that reflect the situation of the organisation (Donaldson, 2001; Hamann, 2017; McAdam et al., 2019). Two main courses of research are considered: the internal fit between organisational characteristics (e.g., organisational strategy, structure, culture, human resource management system or technology), and the fit between organisational and environmental features (Burns \& Stalker, 1961; Donaldson, 2006; Hamann, 2017; McAdam et al., 2019).

The empirical research involved 1142 organisations operating in Poland and Switzerland. The multiple correspondence analysis (MCA) was used to reach the set aim.

\section{CONCEPT OF THE ORGANISA- TIONAL SIMPLEXITY}

It is hard to achieve simplicity in a complex world. Moreover, complexity theorists note that complexity arises from simplicity (Gribbin, 2004). Cunha and Rego (2010) underlie the evolution of organisational thinking into a paradoxical combination of simplicity and complexity, which should permeate each other for an organisation to gain a competitive advantage and achieve success. The concept of simplexity is a compromise that allows combining simplicity (of the structure) and complexity (of the workforce). Authors focus on how a simple design may facilitate the emergence of complex and adaptive collective behaviour (in coexistence and co-evolving). Therefore, two elements will be considered: organisational structure and workforce, underlining that the simplicity of one and the complexity of the other can result in some benefit for organisations.

\subsection{SimPLE STRUCTURE SOLUTION}

The organisational structure emerges as one of the main sources of the excessive complexity of an organisation (Collinson \& Jay, 2012; Leff \& Zolkos, 2015). It is increasingly emphasised that simple structural solutions support flexibility and adaptation of organisations operating under complex, dynamic and unpredictable conditions (Drucker, 1993; Peters \& Waterman, 2004; Welch \& Welch, 2005; Ashkenas, 2007; Cunha \& Rego, 2010; Leff \& Zolkos, 2015), yet the existing structural solutions do not meet the criterion of simplicity. For example, in already cited research of The Economist, more than a half of the 
managers perceived the structure of their organisations as very or extremely complex, and only $1 \%$ of them found the structure to be sufficiently simple (Leff \& Zolkos, 2015). The very concept of a simple structure is still ambiguously understood (HopejKamińska et al., 2015). Therefore, the term will be approximated in the context of different and often conflicting views.

In the literature, the most frequently referenced model of a simple structure has been developed by Mintzberg (1979). It is characterised by a flat, twotier hierarchy, low degree of specialisation, formalisation and standardisation activities as well as a high degree of centralisation. Such a structural solution can be seen as restrictive because within it, one person sets the rules of action for the rest to follow. Therefore, there is little room for manoeuvre. Mintzberg's concept of a simple structure is centred around environmental complexity reduction where "the organisation tries to simplify and reduce the amount of data and the number of choices available to its members. Sense-making is undertaken by only a few agents whose roles place them at the top of the hierarchy" (Ahmos et al., 2002, p. 193). Miller (1993) and Lumpkin and Dess (1995), who share this understanding of a simple structure, also claim that it is not the best solution under complex and changing environmental conditions.

However, a different approach is also present in the literature. Hopej-Kamińska et al. (2015) argue that a simple structural solution is the one, which maximises the freedom of organisation's members. Using fractal calculus, they verified and confirmed the developed concept. Ahmos et al. (2002) emphasise that in the face of increasing environmental complexity, an organisation can not only strive to reduce this complexity but also to absorb it. An organisation must "hold multiple and sometimes conflicting representations of environmental variety, retaining in their behavioural repertoire a range of responses, each of which operates at a lower level of specificity" (Ahmos et al., 2002, p. 193). In such a case, "the simplicity of the structural solution boils down to the limitation and simplification of all topdown imposed rules" (Hopej-Kamińska et al., 2015, p. 264). Hence, the simple structure is a flat structural solution, characterised by a small number of hierarchical levels and a large span of control, low degree of centralisation, formalisation, specialisation and standardisation (Hopej-Kamińska et al., 2015). The second approach is in line with those adopted by Cunha and Rego (2010) in their simplexity concept.

\subsection{COMPLEX WORKFORCE}

According to Cunha and Rego (2010), when the complexity of the organisational environment increases, the structure simplicity comes at the expense of the complexity of other elements in the organisation (which together create some sort of balance needed for the organisation to operate). This notion supports the consistency between the postulate of organisational simplification in the complex world and Ashby's law. It is also is in line with the contingency approach. Discussing the complexity theory in the context of an organisation, Marion (1999, pp. 81-82) adapted the concept of Complex Adaptive Systems (CAS), which is "an adaptive, interactive network of actors (...) structured by physics and teleology (...) refined by selection." This idea can be referenced to the world of organisation where adaptation to the complex environment through simple structure may occur only based on that interactive network of actors, i.e. complex workforce. Moreover, they state that there is a need for some sort of compromise between the simplicity of structure required to adapt to the contingency of the organisational environment and the fact that it should be obtained by internal differentiation - workforce complexity. Also, Cunha and Rego (2010) suggest that it should be clear that the balance can be achieved by connecting a simple organisational structure with a complex workforce, which cannot be avoided in today's world.

It seems to be important to focus on what is workforce complexity. Hase (2002) underlines that the capability of employees should be a goal for every organisation and simultaneously, it is one of the greatest sources of complexity in an organisation. Stephenson and Weil (1992, p. 2) emphasise that it "is not just about skills and knowledge. Taking effective and appropriate action under unfamiliar and changing circumstances involves judgements, values, the self-confidence to take risks and a commitment to learn from the experience." Therefore, it can be said that nowadays, it is almost impossible to secure organisation operations and competitive advantage without such a complex workforce, which is not only characterised by competence but also by capability. The Complexity Theory underlines the importance of being ready for sudden, unaccountable change at any moment and the need for relying excessively on prediction (Hase, 2002; Bieńkowska \& Tworek, 2019). It seems that in the complex environment, the simplification of the organisational structure must be bal- 
anced by the complexity of workforce organised based on this structure. Organisations competing based on simple designs, accept that they may have to cope with external turbulence and flexible networks of highly autonomous individuals and teams as well as by stimulating intrapreneurship (Cunha \& Rego, 2010). Moreover, thanks to competence and capability, the complex workforce can undertake risk and work efficiently, even in a changing environment. Highly talented people do not need, and are unlikely to put up with, an overtly hierarchical management model (Hamel, 2008). Provided with possibilities to participate, they can become change agents. It is a complex workforce that enables adaptive management in a way absorbing a part of outer variability as long as the organisational structure allows.

Therefore, in the context of the above-mentioned literature review, it seems justified to propose the following hypothesis:

$\mathrm{H}$ : The fit between the simplicity of the organisational structure, workforce complexity and selected features of the organisational environment (complexity, dynamics and uncertainty) positively affects the organisational performance.

It has been decided that verification of organisational simplexity concept must be widened and will apply not only to the fit between the simplicity of the organisational structure, workforce complexity and the organisational environment. It has been recognised that organisational environment characteristics have to have a wider perspective because today's organisational world is increasingly more complex and also volatile and, therefore, unpredictable. Moreover, it is crucial to establish the verifying criteria of fit validity, such as organisational performance.

\section{RESEARCH METHODOLOGY}

To verify the hypotheses, a questionnaire was used to conduct a survey. The main survey was preceded by the pilot survey conducted in early 2018, in a group of 50 organisations, to explain the issues concerning the ambiguity of questions. According to the obtained results, the ambiguous questions were rewritten to obtain more informed responses from organisations participating in the main survey. The main research was conducted as a part of a research project No. 2017/01/X/HS4/01967 - "The influence of IT reliability on the quality of management methods and techniques", financed from the funds of the National Science Centre of Poland. It was carried out in March 2018, in a group of organisations located in Poland and Switzerland, which was the only condition limiting the sample (organisations were surveyed regardless of their size, industry or the type of business). Online survey service SurveyMonkey was used. The respondent panel of managers working in organisations of both countries was purchased and used as a poling sample for the research. 558 valid responses were collected from Poland and $564-$ from Switzerland. Respondents were asked to evaluate several organisational issues based on the list of factors using the five-level Likert scale for the measurement of (on the scale from "I strongly disagree" to "I strongly agree" with the middle point "I do not have an opinion"):

- structure simplicity measured based on the item: "Organisational structure of the company is simple";

- workforce complexity measured based on the item: "Employees are independent, proactive and open to new ideas".

- environmental characteristics were also evaluated using the same five-level Likert scale for:

- environmental complexity based on the item: "Company offers different products or services";

- environmental dynamics based on the item: "Company's environment is constantly changing";

- environmental unpredictability based on the item: "Changes in the company's environment are unpredictable."

Since the performed research was intended as a pilot, it was consciously decided to measure each of the phenomena using the one-item technique. Such an approach is valid and can be found in the literature concerning the methodology of research in management sciences (e.g. Fuchs \& Diamantopoulos, 2009).

The organisational performance scale was an exception, as it was based on nine items (return on investment (ROI), sales growth, profit growth, productivity improvement, reduction of emissions, effluent \& waste, reduced use of resources (key materials/ energy/water), improvement of employee satisfaction, improvement of health and safety conditions, the impact on the creation of healthy and liveable communities) and captured the extent, to which organisation achieved organisational performance, including financial and non-financial measures and short-term and long-term measures, covering financial and market performance, quality performance and innovation performance (Crane et al., 2014; Campos et al., 2015; Maletic et al., 2015; Matić, 2012). 
The evolution of the performance during the previous three years was conducted. Respondents were asked to rate the performance using the Likert scale (from "well below expectations" to "well above expectations" with the middle point being "as expected"). In line with the literature, subjective measures of organisational performance were used (Maletic et al., 2015).

The study was based on the 5-point Likert scale due to several reasons. First, the odd-numbered scale was chosen to not force respondents to have a definite opinion, which could have reduced the chance for response bias in social sciences studies (Croasmun \& Ostrom, 2011). Second, 5-point scales are known to have higher scale reliability than those that have 3 points (Hartley, 2014).

To verify the hypothesis, a statistical analysis was carried out. A correlation analysis was performed to initially verify the relationships between the simplicity of the organisational structure and the complexity of the workforce under the conditions of a complex, dynamic and unpredictable environment. As the investigated relationship was initially confirmed, an in-depth analysis was conducted using the multiple correspondence analysis (MCA) method.

\section{RESEARCH RESULTS}

It was assumed that the structure of the relationship between the workforce and the environment must be verified in the context of organisational performance. The verification of the simplexity concept is based on the use of organisational performance as a dependent variable while remaining variables are treated as independent variables. Tab. 1 contains descriptive statistics for all measured variables.

Tab. 1. Descriptive statistics

\begin{tabular}{|c|c|c|c|c|c|}
\hline & $\mathbf{N}$ & MIN & MAX & MEAN & $\begin{array}{c}\text { STD. } \\
\text { DEVIATION }\end{array}$ \\
\hline Environmental dynamics & 1142 & 1.00 & 5.00 & 3.07 & 1.224 \\
\hline Environmental unpredictability & 1147 & 1.00 & 5.00 & 3.10 & 1.163 \\
\hline Environmental complexity & 1145 & 1.00 & 5.00 & 3.04 & 1.214 \\
\hline Structure simplicity & 1146 & 1.00 & 5.00 & 3.03 & 1.190 \\
\hline Complex workforce & 1141 & 1.00 & 5.00 & 3.03 & 1.191 \\
\hline Organisational performance & 1120 & 1.00 & 5.00 & 3.33 & 0.921 \\
\hline
\end{tabular}

Tab. 2. Analysis of the correlation between environment features, the structure simplicity and the workforce complexity (the Spearman's Rho correlation test)

\begin{tabular}{|c|c|c|c|c|c|c|}
\hline & & $\begin{array}{l}\text { STRUCTURE } \\
\text { SIMPLICITY }\end{array}$ & $\begin{array}{l}\text { COMPLEX WORK- } \\
\text { FORCE }\end{array}$ & $\begin{array}{l}\text { ENVIRONMENTAL } \\
\text { DYNAMICS }\end{array}$ & $\begin{array}{l}\text { ENVIRONMENTAL } \\
\text { UNPREDICT- } \\
\text { ABILITY }\end{array}$ & $\begin{array}{l}\text { ENVIRONMENTAL } \\
\text { COMPLEXITY }\end{array}$ \\
\hline \multirow{3}{*}{$\begin{array}{l}\text { Structure } \\
\text { simplicity }\end{array}$} & Correlation & 1.000 & $0.590 * *$ & $0.586 * *$ & $0.551^{* *}$ & $0.509 * *$ \\
\hline & Sig. (2-tailed) & . & 0.000 & 0.000 & 0.000 & 0.000 \\
\hline & $\mathrm{N}$ & 1146 & 1138 & 1139 & 1143 & 1142 \\
\hline \multirow{3}{*}{$\begin{array}{l}\text { Complex } \\
\text { workforce }\end{array}$} & Correlation & $0.590 * *$ & 1.000 & $0.635 * *$ & $0.525^{* *}$ & $0.602 * *$ \\
\hline & Sig. (2-tailed) & 0.000 & . & 0.000 & 0.000 & 0.000 \\
\hline & $\mathrm{N}$ & 1138 & 1141 & 1135 & 1139 & 1136 \\
\hline \multirow{3}{*}{$\begin{array}{l}\text { Environmental } \\
\text { dynamics }\end{array}$} & Correlation & $0.586 * *$ & $0.635^{* *}$ & 1.000 & $0.689 * *$ & $0.583^{* *}$ \\
\hline & Sig. (2-tailed) & 0.000 & 0.000 & . & 0.000 & 0.000 \\
\hline & $\mathrm{N}$ & 1139 & 1135 & 1142 & 1140 & 1137 \\
\hline \multirow{3}{*}{$\begin{array}{l}\text { Environmental } \\
\text { unpredictability }\end{array}$} & Correlation & $0.551 * *$ & $0.525 * *$ & $0.689 * *$ & 1.000 & $0.573 * *$ \\
\hline & Sig. (2-tailed) & 0.000 & 0.000 & 0.000 & . & 0.000 \\
\hline & $\mathrm{N}$ & 1143 & 1139 & 1140 & 1147 & 1142 \\
\hline \multirow{3}{*}{$\begin{array}{l}\text { Environmental } \\
\text { complexity }\end{array}$} & Correlation & $0.509 * *$ & $0.602 * *$ & $0.583^{* *}$ & $0.573^{* *}$ & 1.000 \\
\hline & Sig. (2-tailed) & 0.000 & 0.000 & 0.000 & 0.000 & . \\
\hline & $\mathrm{N}$ & 1142 & 1136 & 1137 & 1142 & 1145 \\
\hline
\end{tabular}

**. Correlation is significant at the 0.01 level (2-tailed) 


\subsection{Correlation anAlysis}

The coefficients of correlation between environmental features, the structure simplicity and the workforce complexity were calculated (Tab. 2).

The results show that the variables are significantly correlated, and the correlation is moderate. It means that the growing structure simplicity is accompanied by the growth of workforce complexity and, at the same time, the growth in complexity, dynamics and unpredictability of the organisation's environment.

\subsection{MulTiPLE CORRESPONDENCE ANALYSIS MODEL}

The multiple correspondence analysis (MCA) is an exploratory technique for categorised variables. It allows creating models of links between different categories of answers. In the case of the study, the analysis allows determining the strongest related variables (response categories) with the study group. As the impact force classifier, the model of distance maximisation from the reference point (the study group) was adopted. Because the main interest was the correspondence with the study group, the points in space for the three studied groups were taken as reference points for other points (responses) and the quality of the solution.

In the MCA model, the division into low, average and high variable results was determined based on a standardised distribution $\mathrm{N}(0 ; 1)$. Values $<-1$ to low values $(\mathrm{L}),>1$ high values $(\mathrm{H})$ and from -1 to 1 average values $(\mathrm{A})$.

The variable Simplexity (Sim) was established. It had 6 values: $0,1,2,3,4$, 5. Each independent variable

Tab. 3. Multiple correspondence analysis model MCA

\begin{tabular}{|c|c|c|c|c|c|c|c|c|c|c|}
\hline & \multirow[b]{2}{*}{ 㟔 } & \multirow[b]{2}{*}{$\sum_{\Sigma}^{n}$} & \multirow{2}{*}{ 売 } & \multirow{2}{*}{ 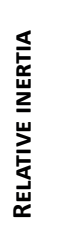 } & \multicolumn{3}{|c|}{ FACTOR 1} & \multicolumn{3}{|c|}{ FACTOR 2} \\
\hline & & & & & 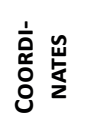 & 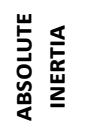 & ูู & 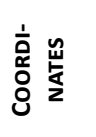 & 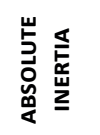 & ภู \\
\hline \multirow{3}{*}{$\begin{array}{l}\text { Environmental } \\
\text { dynamics }\end{array}$} & Ed:L & 0.014 & 0.696 & 0.053 & -1.400 & 0.047 & 0.211 & 2.121 & 0.128 & 0.485 \\
\hline & Ed:H & 0.022 & 0.622 & 0.050 & 1.698 & 0.111 & 0.535 & 0.688 & 0.022 & 0.088 \\
\hline & Ed:A & 0.107 & 0.609 & 0.015 & -0.173 & 0.006 & 0.089 & -0.420 & 0.039 & 0.520 \\
\hline \multirow{3}{*}{$\begin{array}{l}\text { Environmental } \\
\text { unpredictability }\end{array}$} & Eu:L & 0.013 & 0.691 & 0.054 & -1.419 & 0.044 & 0.197 & 2.247 & 0.132 & 0.494 \\
\hline & Eu:H & 0.022 & 0.644 & 0.050 & 1.747 & 0.114 & 0.547 & 0.737 & 0.024 & 0.097 \\
\hline & Eu:A & 0.108 & 0.638 & 0.014 & -0.183 & 0.006 & 0.105 & -0.411 & 0.038 & 0.533 \\
\hline \multirow{3}{*}{$\begin{array}{l}\text { Structure sim- } \\
\text { plicity }\end{array}$} & $S: L$ & 0.015 & 0.593 & 0.053 & -1.244 & 0.041 & 0.186 & 1.841 & 0.106 & 0.407 \\
\hline & S:H & 0.021 & 0.576 & 0.050 & 1.676 & 0.101 & 0.481 & 0.743 & 0.024 & 0.095 \\
\hline & S:A & 0.107 & 0.561 & 0.015 & -0.150 & 0.004 & 0.066 & -0.410 & 0.037 & 0.495 \\
\hline \multirow{3}{*}{$\begin{array}{l}\text { Environmental } \\
\text { complexity }\end{array}$} & Ec:L & 0.016 & 0.597 & 0.052 & -1.302 & 0.047 & 0.213 & 1.747 & 0.100 & 0.384 \\
\hline & Ec:H & 0.023 & 0.518 & 0.049 & 1.513 & 0.089 & 0.433 & 0.671 & 0.021 & 0.085 \\
\hline & Ec:A & 0.104 & 0.508 & 0.016 & -0.131 & 0.003 & 0.046 & -0.414 & 0.037 & 0.462 \\
\hline \multirow{3}{*}{$\begin{array}{l}\text { Complex work- } \\
\text { force }\end{array}$} & Cw:L & 0.014 & 0.594 & 0.053 & -1.365 & 0.045 & 0.205 & 1.882 & 0.103 & 0.389 \\
\hline & Cw:H & 0.023 & 0.587 & 0.050 & 1.628 & 0.103 & 0.498 & 0.687 & 0.022 & 0.089 \\
\hline & Cw:A & 0.106 & 0.534 & 0.015 & -0.165 & 0.005 & 0.078 & -0.397 & 0.034 & 0.456 \\
\hline \multirow{6}{*}{ Simplexity } & Sim:0 & 0.054 & 0.342 & 0.036 & -0.725 & 0.049 & 0.322 & 0.181 & 0.004 & 0.020 \\
\hline & Sim:1 & 0.021 & 0.048 & 0.050 & -0.331 & 0.004 & 0.019 & -0.401 & 0.007 & 0.028 \\
\hline & Sim:2 & 0.023 & 0.034 & 0.050 & -0.047 & 0.000 & 0.000 & -0.426 & 0.008 & 0.034 \\
\hline & Sim:3 & 0.015 & 0.038 & 0.053 & 0.475 & 0.006 & 0.027 & -0.316 & 0.003 & 0.012 \\
\hline & Sim:4 & 0.010 & 0.094 & 0.055 & 1.080 & 0.021 & 0.090 & 0.232 & 0.001 & 0.004 \\
\hline & Sim:5 & 0.019 & 0.409 & 0.051 & 1.522 & 0.077 & 0.360 & 0.560 & 0.012 & 0.049 \\
\hline \multirow{3}{*}{$\begin{array}{l}\text { Organisational } \\
\text { performance }\end{array}$} & Op:L & 0.019 & 0.238 & 0.051 & -0.862 & 0.024 & 0.112 & 0.916 & 0.032 & 0.126 \\
\hline & Op:H & 0.028 & 0.413 & 0.047 & 1.047 & 0.052 & 0.263 & 0.790 & 0.035 & 0.150 \\
\hline & Op:A & 0.096 & 0.376 & 0.019 & -0.133 & 0.003 & 0.037 & -0.404 & 0.032 & 0.340 \\
\hline
\end{tabular}


was categorised: values 1, 2, 3 were given 0 , and values 4,5 were given 1 . Hence, the sum was just the sum of 1 s. If among 5 variables, the chosen values were 4 or 5 , the sum was 5 . In the case all variables were below 4 , the sum was 0 .

The results of the MCA analysis are presented in the Tab. 3. The chosen model is statistically significant: Chi2(529) $=38898 ; \mathrm{p}<0.01$.

The MCA model shows several significant findings. Firstly, in accordance with all independent variables (structure simplicity, workforce complexity and all three environmental characteristics), for each of them, the low values were accompanied by the low values of others (and similarly for medium and high values). Therefore, the following conclusions can be made:

- in the dynamic, complex and unpredictable environment, there is a concomitance between structure simplicity and complex workforce;

- in a stable, simple and predictable environment, the opposite situation occurs: the complex structure is accompanied by a simple workforce;

- medium average environment characteristics coexist with a medium level of structure simplicity and workforce complexity.
Secondly, the high value of independent variables is accompanied by a high level of organisational performance (and similarly for medium values). It can, therefore, be underlined that there is a relationship between variables of the simplexity (Sim) and the organisational performance (Op). It has been arbitrary established that organisational performance is a dependent variable. When simplexity reaches the level of 4 or 5 , the organisational performance also reaches high values, while 0 to 3 values for simplexity level indicate average organisational performance. That is a particularly interesting result that means that although there is the fit between structure simplicity, complex workforce, environmental dynamics, unpredictability and complexity, such fit does not necessarily lead to higher organisational performance. Therefore, the obtained results are not sufficient to accept the proposed hypothesis.

\section{DISCUSSION}

The empirical results are inconclusive, and do not allow for the unambiguous acceptance of the research hypothesis $\mathrm{H}$ : The fit between the simplicity

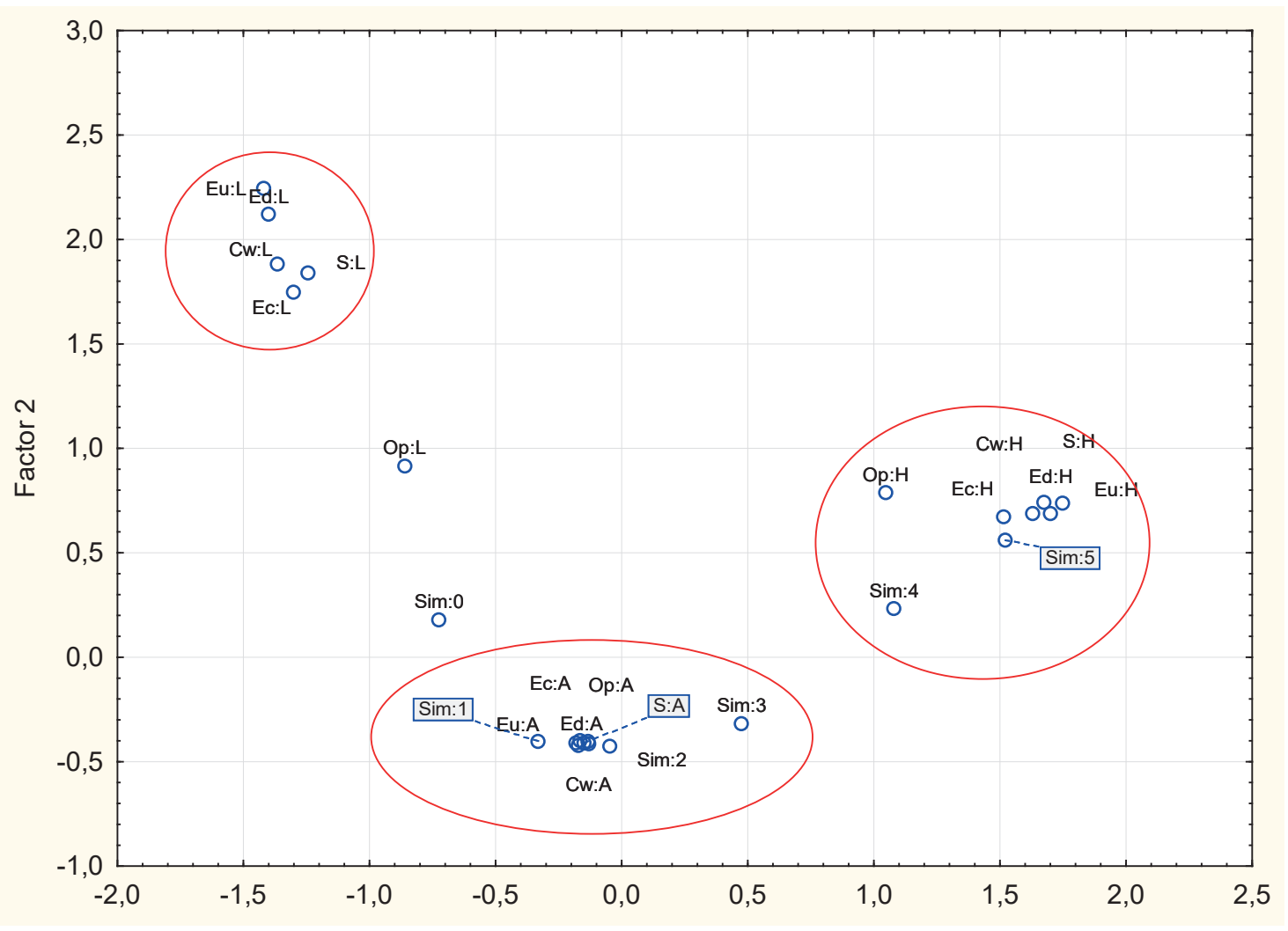

Fig. 1. Chart of projection of multidimensional space of MCA characteristics into a two-dimensional space 
of the organisational structure, workforce complexity and selected features of the organisational environment (complexity, dynamics and uncertainty) positively affects the organisational performance. The hypothesis was confirmed only for organisations operating in a highly dynamic, complex and unpredictable environment.

A significant fit was established between the structure simplicity and the workforce complexity in examined organisations, adequate to environmental features. A more complex, dynamic and uncertain environment aligned with more complex workforce and simpler structural solutions. Therefore, the organisational simplexity concept by Cunha and Rego (2010) was empirically proven. However, the study results should be related to the core elements of the contingency theory. Not only the contingency factor and the organisational system must be associated (and a change in the contingency factor must cause a change in the organisational system), but also a fit between the contingency factor and the organisational system should positively affect the performance of this system (Donaldson, 2001; Harmann, 2017). Although there is a fit between studied organisational characteristics (structure simplicity and workforce complexity) and organisational environment features (complexity, dynamics and uncertainty), only in the case of a highly complex, dynamic and uncertain environment, this fit leads to high organisation performance. The results are inconclusive for other types of environment. Therefore, the study can bring direct recommendations only for organisations operating in a complex, dynamic and uncertain environment. Considering that most contemporary organisations operate in such conditions, the obtained results seem to fill an important research gap.

The research results support the concept of a simple structural solution that is centred around the absorption of the environmental complexity rather than its reduction. Accepting that the organisational structure is as a set of rules ordering the behaviour of the organisation's members (Hopej-Kamińska et al., 2015), it can be stated that the simpler is the structural solution, the more freedom it gives organisational members (and the fewer restrictions it imposes on them). It is in line with the views on the concept of a simple organisational structure of such authors as Ahmos et al. (2002), Cunha and Rego (2010) or Hopej-Kamińska et al. (2015). However, it is in contrary to classical views of Miller (1993), Lumpkin and Dess (1995) or, in the centralisation dimension, to the
Mintzberg (1979) concept of a simple structure. The research supports the first approach, as it was proven that in surveyed organisations, the more complex (and also more dynamic and uncertain) organisational environment was coexisting with simpler organisational structures. Traditionally, authors consider the simple structure as appropriate mainly for young organisations, which are rather small. It would be important to incorporate the size and the age of organisations to further research the relationship between the structure simplicity and environmental features.

The conducted research shed some new light on strategies, methods and tools aimed at simplifying organisations (e.g. Ashkenas, 2007; Collinson \& Jay, 2012; Segall, 2016; Bodell, 2016) and organisational elements (e.g. Eisenhardt \& Sull, 2001; Peters \& Waterman, 2004; Maeda, 2006; Ashkenas, 2007; Osbert-Pociecha, 2013; Segall, 2013; Brandes, 2013; Hopej et al., 2017) proposed by various authors.

First, most studies to date are dominated by the focus on simplifying organisations in all considered dimensions, they abstract from the relationship between various aspects of an organisation, and also from the external organisational context (e.g. Ashkenas, 2007; Leff \& Zolkos, 2015; Segall, 2016). The presented research shows that the concept of organisational simplicity cannot concern the simultaneous simplification of all elements of an organisation. This result is in line with Ashby's law and means that simplifying certain aspects of an organisation requires an increase in the complexity of others, always in the context of the organisation's environment. According to the study, the simplification of the organisational structure must be accompanied by conscious efforts to develop staff competences so that employees can behave freely and efficiently while undertaking necessary decisions and actions. This result, although limited only to few organisational simplicity elements, reveals that the organisational simplicity concepts and methods formulated so far must be verified. The notion of organisational simplicity is not that simple. To conceptualise it, extended research is required, i.e. research verifying the relationship between the simplicity of different organisational elements and organisational simplicity and organisational performance in different business contexts.

Most proposals in the field of organisational simplicity are of a theoretical nature, possibly supported by case studies. The extended empirical research is very limited, mainly the studies of Leff and 
Zolkos (2015), Kamińska-Hopej et al. (2015) and Collinson and Jay (2012). The research presented in this article may enrich the results obtained by other authors, open new research directions and even, to some extent, undermine some results.

Leff and Zolkos (2015) examined the views of managers regarding the causes of excessive complexity, ways of dealing with them and ways of measuring results of encouragement. However, they did not refer to the relationship between various dimensions of simplicity, nor did they consider the external context of the organisation's operations.

Hopej-Kamińska et al. (2015) focused on the problem of simplifying the organisational structures, and they conducted a pilot study on a sample of 100 Polish organisations. The study demonstrated that the simplicity of the structure was correlated with the size of the organisation, the diversification of the activity, the manufacturing technology, the strength of the relations of the organisation with the environment, corporate culture as well as with the management's attempts to simplify the organisation. The current research is an extension of those obtained by Hopej-Kamińska et al. Not only it proves that there is a significant relationship between the simplicity of the organisational structure and the workforce complexity (a factor not included in the quoted study). Moreover, based on the contingency approach, the relationship was identified to organisational performance in the context of different situational conditions. The presented research, along with those carried out by Hopej-Kamińska et al. (2015), may be a starting point for further research: both studies contribute to the development of knowledge about the relationship between the level of simplicity of various organisational elements and organisational environment, and the study described in this article additionally indicates the importance of compatibility between different elements of an organisation and its environment with regard to their simplicity/complexity.

A reference should also be made to the results of empirical studies conducted by Collinson and Jay (2012). These researchers were the only ones who conducted in-depth empirical research into the relationship between the organisational complexity (they treated simplicity as the opposite of complexity) and organisational performance. Six dimensions of complexity were distinguished: one external (environmental complexity) and five internal (product, strategy, people, design and process). 200 organisa- tions form Global Fortune 500 were analysed according to their complexity and performance. Collinson and Jay (2012) found that the relationship between performance and complexity is best characterised by an inverted-U-shaped curve. As a result, they distinguished two types of organisational complexity: good and bad. Good complexity creates additional value (performance increases as complexity increases), bad complexity increases cost and destroys value (performance decreases as complexity increases). The main result of the research by Collinson and Jay (2012) is the formulation of simplification strategies (related to complexity dimensions) focused on unleashing organisational performance. The quoted study stands out in terms of the adopted research method and of relating the concept of organisational simplicity/ complexity to organisational performance. They also recognise that organisations can be not only too complex but also not complex enough. At the same time, due to theoretical assumptions, they clearly follow the dominant approach of the simultaneous simplification of all elements of an organisation (dimensions of organisational complexity). It should be emphasised again that the empirical research described in this article proves that the concept of organisational simplicity cannot mean the simultaneous simplification of all elements of an organisation. In this context, the interpretation of the inverted-Ushaped curve, showing the relationship between performance and complexity, developed by Collinson and Jay (2012), should be considered. The inverted$\mathrm{U}$-shaped curve may mean that for other situations than 'optimal', according to Collinson and Jay (2012) (when the level of complexity relates to the highest level of performance), the fit between external conditions and internal dimensions of complexity is not appropriate, or the fit between complexity of different internal organisational elements is not appropriate. For example, in relation to the performed research, the simultaneous increase in the simplicity of organisational structure and workforce would not have a positive effect on organisational performance (the performance would be the highest for average structure and workforce complexity). From this perspective, the presented research prompts to reconsider the results obtained by Collinson and Jay (2012).

Hence, the final theoretical implications of the presented research may be formulated. The concept of organisational simplexity is more promising than the notion of organisational simplicity or organisational complexity, as it reveals the need to adjust the 
level of simplicity and complexity of various elements of an organisation. Wherein, the reconceptualization of organisational simplexity is required as adapting only two organisational elements proposed by Cunha and Rego (2010) is not sufficient. First, no significant correlation between the adapted concept of organisational simplexity and organisational performance for other than the most complex, uncertain and unpredictable environmental conditions, calls for reconceptualization. Secondly, several factors are considered in the literature as important for the notion, among others: organisational strategy, leadership style, technology, culture, processes, information technology (Maeda, 2006; Ashkenas, 2007; Collinson \& Jay, 2012; Osbert-Pociecha, 2013; Segall, 2013; Brandes, 2013; Kamińska-Hopej et al., 2015; Segall, 2016; Bodell, 2016; Hopej et al., 2017). It must be emphasised that any research on the concept of simplexity should be embedded in the contingency theory. It allows for the integration of seemingly contradictory efforts to increase the simplicity of certain elements of the organisation and at the same time, increase the complexity of others. Additionally, the contingency theory supports the rejection of perceiving the organisational simplicity as an unquestioned value and aim and accepting that the level of organisational simplicity/complexity must be related to the positive organisational effectiveness.

The limitations of the research must be pointed out. According to the contingency theory, several endogenous and exogenous factors could be included in the survey. However, the study was limited only to two organisational characteristics and three environmental features, since the main aim of the paper was to empirically verify the concept of organisational simplexity. The empirical research also has its limitations. It was performed only in two business contexts (Poland and Switzerland) and requires further analysis. Although every effort was made to ensure that the respondents have extensive knowledge about the operations of the organisation (the sample was limited to managers), it would be important to expand the research in the future using other measurement methods of considered issues (e.g. organisational document analysis, surveys of different groups of employees, KPIs). Finally, the research was carried out only one time in each organisation. Since, according to the contingency approach, interaction fit is particularly important, it requires conducting a longitudinal survey, and it seems that further studies are also required.

\section{LITERATURE}

Ahmos, D. P., Duchon, D., McDaniel, R. R. Jr, \& Huonker, J. W. (2002). What a Mess! Participation as a Simple Managerial Rule to 'Complexify' Organizations. Journal of Management Studies, 39(2), 189-206. doi: 10.1111/1467-6486.00288

Ashkenas, R. (2007). Simplicity-Minded Management. Harvard Business Review, 85(12), 101-109.

Bieńkowska, A., \& Tworek, K. (2019). Job performance model based on Employees' Dynamic Capabilities (EDC). Raporty Wydziału Informatyki i Zarządzania Politechniki Wrocławskiej, Ser. PRE nr 7 [Reports of the Faculty of Computer Science and Management of the Wrocław University Science of Technology, Ser. PRE No. 7].

Bodell, L. (2016). Why Simple Wins: Escape the Complexity Trap and Get to Work That Matters. Routledge.

Brandes, D. (2013). Einfach managen: Komplexität vermeiden, reduzieren und beherrschen. Frankfurt, Germany: Redline Verlag.

Burns, T., \& Stalker, G. M. (1961). The management of innovation. London, Great Britain: Tavistock.

Campos, L. M. S., de Melo Heizen, D. A., Verdinelli, M. A., \& Cauchick, M. P. A. (2015). Environmental performance indicators: A study on ISO 14001 certified companies. Journal of Cleaner Production, 99, 286296. doi: 10.1016/j.jclepro.2015.03.019

Collinson, S., \& Jay, M. (2012). From Complexity to Simplicity: Unleash Your Organisation's Potential. Palgrave Macmillan.

Crane, A., Palazzo, G., Spence, L. J., \& Matten, D. (2014). Contesting the value of "creating shared value". California Management Review, 56(2), 130-153. doi: 10.1525/cmr.2014.56.2.130

Croasmun, J. T., \& Ostrom, L. (2011). Using Likert-Type Scales in the Social Sciences. Journal of Adult Education, 40(1), 19-22.

Crozier, M. (1993). Przedsiębiorstwo na podstuchu [L'Entreprise à l'écoute]. Warszawa, Poland: PWE.

Cunha, M. P., \& Rego, A. (2010). Complexity, Simplicity, Simplexity. European Management Journal, 28, 8594. doi: 10.1016/j.emj.2009.04.006

Donaldson, L. (2001). The contingency theory of organizations. Sage Publications.

Donaldson, L. (2006). The contingency theory of organizational design: challenges and opportunities. In R. M. Burton, B. Eriksen, D. D. Håkonsson, \& C. C. Snow (Eds.), Organization Design. The Evolving State-of-the-Art (pp. 19-40). Boston: Springer. Retrieved from https://link.springer.com/ book/10.1007/0-387-34173-0

Drucker, P. (1993). The Practice of Management, New York, United States: Harper Business.

Eisenhardt, K. H., \& Sull, D. N. (2001). Strategy as Simple Rules. Harvard Business Review, 79(1), 106-116.

Fuchs, C., \& Diamantopoulos, A. (2009). Using single-item measures for construct measurement in management research: Conceptual issues and application 
guidelines. Die Betriebswirtschaft, 69(2), 195-210. Retrieved from https://temme.wiwi.uni-wuppertal. de/fileadmin/_migrated/content_uploads/fuchs_ diamantopoulos_2009.pdf

Gribbin J. (2004). Deep Simplicity: Chaos, Complexity and the Emergence of Life, London, Great Britain: AllenLane.

Hamann, P. M. (2017). Towards a contingency theory of corporate planning: a systematic literature review. Management Review Quarterly, 67(4), 227289. Retrieved from https://link.springer.com/article/10.1007/s11301-017-0132-4

Hamel, G. (2008). The future of management. Human Resource Management International Digest, 16(6). doi: 10.1108/hrmid.2008.04416fae.001

Hartley, J. (2014). Some thoughts on Likert-type scales. International Journal of Clinical and Health Psychology, 14(1), 83-86. doi: 10.1016/S1697-2600(14)700407

Hase, S. (2002), Simplicity in complexity: Capable people and capable organisations need each other. Paper presented at the Australian Vocational Education and Training Association conference, Melbourne, April.

Hopej, M., Kamiński, R., Tworek, K., Walecka-Jankowska, K., \& Zgrzywa-Ziemak, A. (2017). Community-oriented culture and simple organizational structure. Organization and Management, 4A, 75-93. Retrieved from http://kolegia.sgh.waw.pl/pl/KZiF/czasopisma/ oik/numery/Documents/2017_NR_4A_(179).pdf

Hopej-Kamińska, M., Zgrzywa-Ziemak, A., Hopej, M., Kamiński, R., \& Martan, J. (2015). Simplicity as a Feature of an Organizational Structure. Argumenta Oeconomica, 1(34), 259-276. doi: 10.15611/ aoe.2015.1.10

Leff, S., \& Zolkos, R. (2015). Taming organisational complexity - start at the top, A report from The Economist Intelligence Unit. Retrieved from https:// eiuperspectives.economist.com/sites/default/files/ EIU_SAP_Taming\%20organisational\%20complexity_PDF_0.pdf

Lumpkin, G. T., \& Dess, G. G. (1995). Simplicity as a Strategy-making Process: The Effects of Stage of Organizational Development and Environment on Performance. Academy of Management Journal, 38(5), 1386-1407. doi: 10.5465/256862

Maeda, J. (2006). The Laws of Simplicity. Design, Technology, Business, Life. Cambridge, Great Britain: MIT Press.

Maletic, M., Maletic, D., Dahlgaard, J., Dahlgaard-Park, S. M., \& Gomišcek, B. (2015). Do corporate sustainability practices enhance organizational economic performance? International Journal of Quality and Service Sciences, 7(2), 184-200. doi: https://doi. org/10.1108/IJQSS-02-2015-0025

Marion, R. (1999). The edge of organization: Chaos and complexity theories of formal social systems, SAGE. doi: $10.4135 / 9781452234052$

Matić, I. (2012). Measuring the effects of learning on business performances: Proposed performance measurement model. The Journal of American Academy of Business, Cambridge, 18(1), 278-284. Retrieved from http://www.jaabc.com/Jaabc18-1September2012Matic.html
McAdam, R., Miller, K., \& McSorley, C. (2019). Towards a contingency theory perspective of quality management in enabling strategic alignment. International Journal of Production Economics, 207, 195-209. doi: https://doi.org/10.1016/j.ijpe.2016.07.003

Miller, D. (1993). The Architecture of Simplicity. The Academy of Management Review, 18(1), 116-138. doi: 10.5465/amr.1993.3997509

Mintzberg, H. (1979). The Structuring of Organizations: A Synthesis of the Research. New Jersey, United States: Prentice Hall.

Morrish, J. (2008). Simplicity: Not as Easy as it Looks. Management Today, April, 43-45.

Osbert-Pociecha, G. (2013). Zmiany upraszczające w organizacji - wyniki badań sondażowych [Simplifying changes in the organization - results of survey research]. Nauki o Zarzadzaniu, 4(17), 95-108. Retrieved from http://cejsh.icm.edu.pl/ cejsh/element/bwmeta1.element.desklight-78d3caad-72f8-4bb8-a554-d6f40bd961a1?q=bwmeta 1 . element.desklight-33961a22-3c1e-43be-8f3f6e62c8de0b32;7\&qt=CHILDREN-STATELESS

Peters, T., \& Waterman, R. (2004). In Search of Excellence: Lessons from America's Best-Run Companies. New York, United States: Harper Business Essentials.

Sandlin, J. A., \& Walther, C. S. (2009). Complicated Simplicity. Moral Identity Formation and Social Movement Learning in the Voluntary Simplicity Movement. Adult Education Quarterly, 59(4), 298-317. doi: 10.1177/0741713609334137

Scherer, J., Hartschen, M., Bruegger, C., \& Hagmann, P. J. (2013). Simplicity for Business Success! Strategies for Simple Products, Services and Processes. Offenbach, Germany: Verlag.

Segall, K. (2013). Insanely Simple: The Obsession That Drives Apple's Success, New York, United States: Penguin Group.

Segall, K. (2016). Think simple: how smart leaders defeat complexity. New York, United States: Penguin.

Stephenson, J., \& Weil, S. (1992). Four themes in educating for capability. Quality in Learning. A Capability Approach in Higher Education. London, Great Britain: Kogan Page.

Welch, J., \& Welch, S. (2005). Winning. New York, United States: Harper Business. 